\title{
Case Analysis of Construction Management in Small Projects in Jeju, Korea
}

\author{
Sang-Chan Kang ${ }^{1}$ and Myunghoun Jang ${ }^{2 *}$ \\ ${ }^{1}$ CEO, NaNum Construction Management Co., Ltd., 14 Gil 21 Joongang-ro, Jeju, Jeju, 63169, \\ Republic of Korea \\ ${ }^{2}$ Professor, Department of Architectural Engineering, Jeju National University, 102 Jejudaehak-ro, \\ Jeju, Jeju, 53243, Republic of Korea. jangmh@jejunu.ac.kr
}

\begin{abstract}
It is difficult to build small houses in a urban or rural region because an owner meets lots of risks from planning, feasible study, estimation, and design to construction. Conflicts or disputes owing to the improper communication between stakeholders like the owner, designer, contractor, sub-contractor, and manufacturer may cause the construction project to delay or stop. Thus, construction management can be a key success factor to the small construction projects. Many construction projects are built in Jeju. The middle and large projects have competent management personnels, but the small projects need a person or a company to help to complete the project goals. This research shows two case projects. One is a multi-family residence in an urban area and the other is a single-family house in a rural area in Jeju. A construction manager participates in both projects to support the owner. And the research proposes the clientcustomized construction management platform for small construction projects.
\end{abstract}

\section{Introduction}

An owner who wants to build a private or multi-family house has to manage design and construction by himself/herself. He/She meets meet an architect to design the house, estimates construction costs, and selects a contractor to build the house by completed drawings. Because it is very difficult to choose an architect and a contractor for an owner with a little knowledge about architecture, construction management (CM) to support the owner gradually becomes familiar in South Korea.

The annual CM capacity appraisal is conducted every year in order to help clients select a construction manager. According to the 2016 appraisal [1], annual results in public and private sectors are almost the same. Most of the companies that have submitted their performance results are large-scale construction companies or construction management companies. The $\mathrm{CM}$ performance assessment is difficult to apply to small construction projects. Active construction management has not been applied to small- and medium-sized construction projects. [2]

\footnotetext{
* Corresponding author: jangmh@jejunu.ac.kr
} 
In most cases, the client is dependent on the contractor to perform the tasks necessary for carrying out the business, or is advised by the architect through the participation of the design company. Some housing associations work partly with the help of a professional consultant if necessary. However, the advice of the professionals is possible for the field, but there are limitations on the advice and direction of the overall construction, and it is limited to some tasks, so it does not cover the overall construction work. [3]

Recently, the construction industry in Jeju has been stagnating, but a lot of construction projects have been taking place in Jeju for a number of years. [4] Large-scale projects are carried out under the construction company's own capabilities or under the support of CM companies. However, small-scale private sector housing construction market is difficult to utilize middle-sized and large-scale CM companies, and small-scale CM companies are also insufficient. Thus, CM companies are necessary to support the design, construction and supervision of small-scale construction projects such as private homes.

It is difficult for the owner of a private house or a multi-family residence to use middle or large CM companies. This study analyzes the case of small CM projects in Jeju and suggests development direction of a small-scale CM company.

\section{Construction management}

\subsection{Work scope of CM}

Since the introduction of the CM in Korea in December 1996, the CM market has been regarded as a service market somewhat similar to the construction inspection. However, in May 2011, the Korean government introduced the CM at risk in the construction industry in order to advance the construction industry and diversify the bidding method. As a result, subcontractors as well as general contractors are interested in the CM at risk. [5]

$\mathrm{CM}$ refers to the management of planning, feasibility study, analysis, design, procurement, contracting, construction control, supervision, evaluation or follow-up management of construction projects. [6] CM is divided into CM for fee and CM at risk. The CM for fee means performing comprehensive and systematic management from planning, design, construction and post-management on behalf of the owner in a construction project. The CM at risk is a contract for the construction industry that registers the construction industry and conducts $\mathrm{CM}$ at the pre-construction stage for the construction work. At the construction stage, the contractor also issues a comprehensive plan, completes construction on site within the construction time and budget.

The scope of work according to construction execution stage of CM is classified into predesign stage, basic design stage, implementation design stage, procurement stage, construction stage, and post-construction stage. Step-by-step work includes basic design and feasibility study management, contract management, design management, cost management, time management, quality control, safety management, environmental management, project information management, and post-construction management, as shown in Figure 1. 


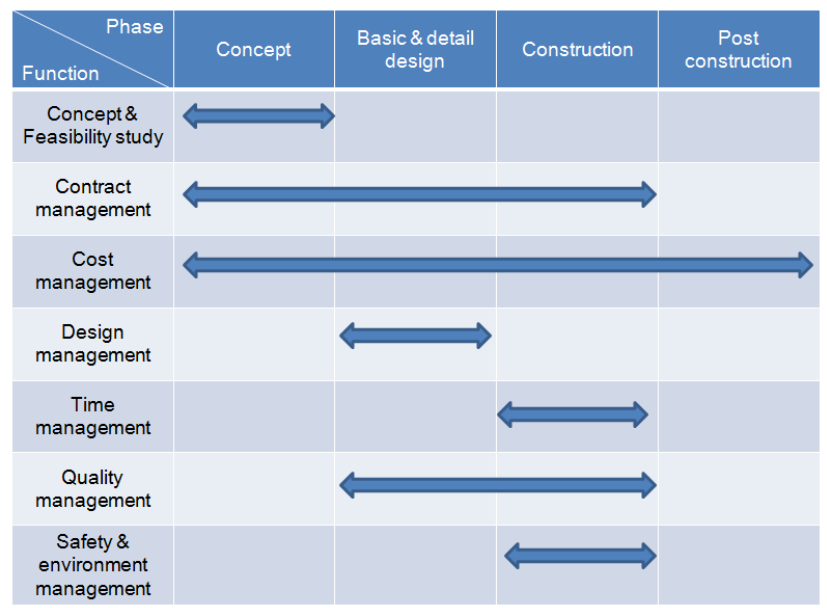

Fig. 1. Scope of construction management.

\subsection{CM capacity appraisal}

The appraisal and public announcement of CM capacity has been carried out every year since 2003. CM results, financial status, manpower status, and credit evaluation reports are evaluated. The results of the evaluation are published in the Construction Industry Knowledge Information System (KISCON) [1] at the end of August every year.

Figure 2 shows the CM results that are on the rise. From the 2015 evaluation, CM for fee and $\mathrm{CM}$ at risk are separately evaluated. As a result of the 2016 evaluation, the CM for fee for 2015 are KRW 419 billion and CM at risk are KRW 278 billion. The results of CM at risk are about twice of the previous year's results.

The results of CM capacity appraisal in 2016 include a large number of domestic and overseas large-scale development projects or construction projects. Table 1 shows the results of $\mathrm{CM}$ for fee contracted in 2015. Of the total 540 cases, 6 cases $(1.1 \%)$ were less than 10 million won, and 138 cases $(25.6 \%)$ were less than 100 million won and over 100 million won. Most of them (73.1\%) earned less than 100 million won (256 cases) and less than 1 billion won and less than 10 billion won (139 cases).

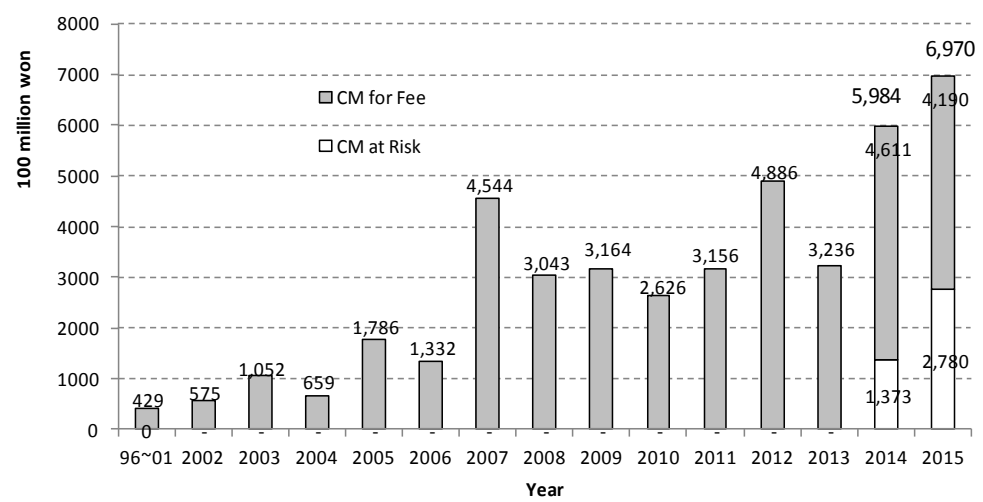

Fig. 2. Amounts of CM performance by year (source from KISCON) 
Table 1. CM for fee contracts in 2015 (source from KISCON)

\begin{tabular}{|c|c|c|}
\hline Contract Price (million won) & No. of Contracts & Ratio (\%) \\
\hline $0 \sim 10$ & 6 & 1.1 \\
\hline $10 \sim 100$ & 138 & 25.6 \\
\hline $100 \sim 1,000$ & 256 & 47.4 \\
\hline $1,000 \sim 10,000$ & 139 & 25.7 \\
\hline $10,000 \sim$ & 1 & 0.2 \\
\hline Total & 540 & 100.0 \\
\hline
\end{tabular}

\section{Small construction management cases}

\subsection{Summary of case projects}

A number of buildings are being constructed not only in urban areas but also in suburbs due to the boom in the construction industry in Jeju. In the urban areas, many people want to get rental income by constructing a multi-family house by high land prices. In the suburbs, there are many private houses for residence.

Small-scale CM is applied to a multi-family house (Project A) and a private house (Project B) as shown in Table 2. The multi-family house consists of two buildings with the same size and purpose as shown in Figure 3. It is located in an urban area. The first floor is used for neighbourhood facilities, and the second floor is composed of two multi-family houses and the third and fourth floor are composed of one multi-family house. The private residence is located in a rural area shown in Figure 4. The total floor area is about $145 \mathrm{~m}^{2}$ and the construction period is 7 months.

Table 2. Summary of case projects.

\begin{tabular}{|c|c|c|}
\hline Category & Project A & Project B \\
\hline Type & Multi-family housing & Single-family housing \\
\hline Total floor area & $466.56 \mathrm{~m}^{2}$ & $145.49 \mathrm{~m}^{2}$ \\
\hline Stories & 4 & 2 \\
\hline Construction duration & 9 months & 7 months \\
\hline Budget (million won) & 940 & 250 \\
\hline
\end{tabular}

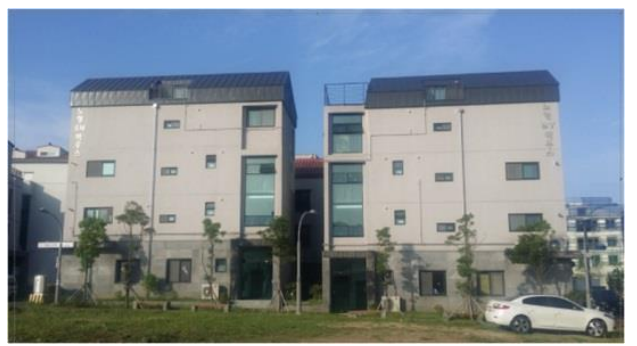

Fig. 3. Project A.

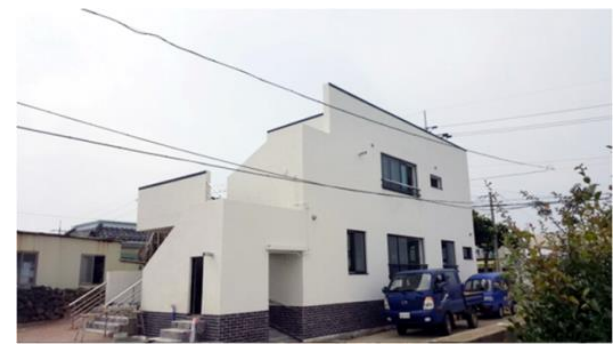

Fig. 4. Project B. 


\subsection{Analysis of case projects}

A construction manager participated in Project A and Project B and his company with two employees is headquartered in Jeju. The construction manager participated at the time of completion of the architectural design and presented the alternatives to review the drawings and selected the construction company. In addition, he consulted designers and constructors on behalf of the architects during the construction process to draw up directions for improvement of drawings and construction methods.

In the project $\mathrm{A}$, various alternatives were suggested by reviewing the existing design for each floor. For example, single and strip footings were changed to mat foundation to ensure better safety. The stairway door on the first floor was changed from the hinged door to the automatic door, and the floor height of the second floor was increased from $2,700 \mathrm{~mm}$ to $2,800 \mathrm{~mm}$. Table 3 shows other design changes.

Table 3. Recommended designs of Project A.

\begin{tabular}{|c|c|c|}
\hline Category & Original design & Recommended design \\
\hline Foundation & $\begin{array}{c}\text { Individual footing } \\
\text { Strip footing }\end{array}$ & Mat foundation \\
\hline Stairway door & Sliding type & Automatic sliding type \\
\hline Window in 1F toilet & $\begin{array}{c}800 * 600 \\
\text { (wide type) }\end{array}$ & $\begin{array}{c}600 * 800 \\
\text { (projected type) }\end{array}$ \\
\hline Floor height $(2 \mathrm{~F})$ & $2,700 \mathrm{~mm}$ & $2,800 \mathrm{~mm}$ \\
\hline Re-bars on 4F slab & D13+D16@100 & D13@125 \\
\hline \multicolumn{2}{|c}{ (The rest is omitted.) } \\
\hline
\end{tabular}

Project B was designed to be used as a private residence for one household with 2 floors. Table 4 shows various alternatives suggested by the construction manager. Among the proposals, there are alternatives to separate the first and second floor by adding a slab to the living room space connected to the first and second floor as shown in Fig. 5. As a result, the building, which was a one-family house, was extended to a two-family house where the first and second floors can be used individually.

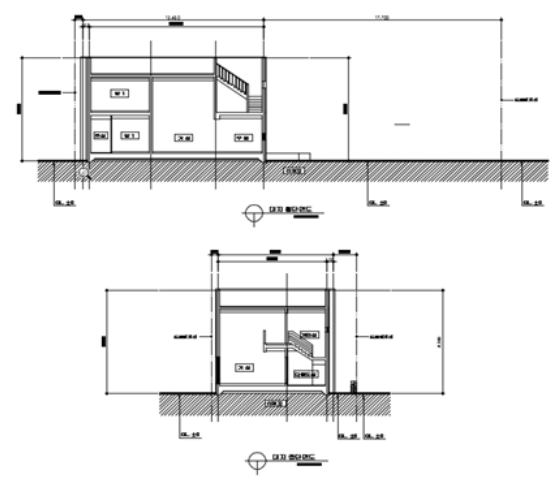

(a) Original design

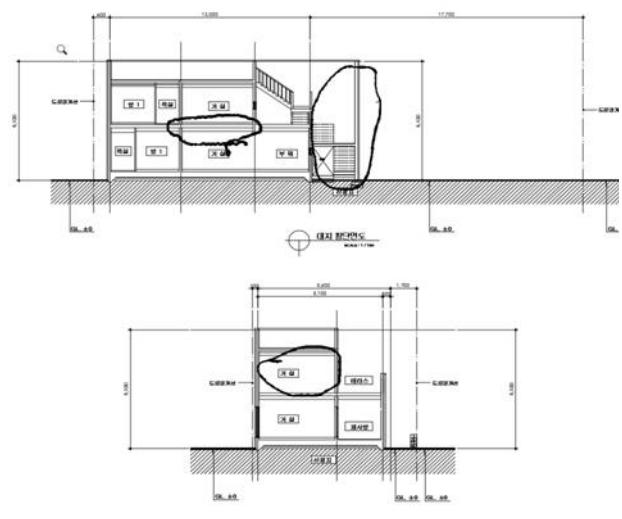

(b) Recommended designs

Fig. 5. Design changes in Project B. 
Table 4. Recommended designs of Project B.

\begin{tabular}{|c|c|c|}
\hline Category & Original design & Recommended design \\
\hline Stairs & Inside 1 st floor & Outside of house \\
\hline Utility room & Inside & Under outside- stairs \\
\hline Living room (2F) & None & Added \\
\hline Parking lots & 1 & 2 \\
\hline Parking lot to front door & $\begin{array}{c}\text { Parking lot - ramp } \\
\text { - front door } \\
\text { (The rest is omitted.) }\end{array}$ & Parking lot - front door \\
\hline \multicolumn{3}{|c}{} \\
\hline
\end{tabular}

\subsection{Results of case projects}

Project A and Project A is planned to be 9 months from the planning/design stage to the completion and the total construction cost is set at 940 million won. The construction period of project B was 8 months and the total construction cost was 250 million won. By applying construction project management to each project as shown in Table 5, the construction period of the project A was shortened by one month and the project B by 1.5 months. After completion of the basic design of both projects, the construction project manager participated. In the detailed design stage and construction stage, the construction period was shortened by smoothly performing the construction in consultation with the client, the designer, and the contractor.

Table 5. Durations of Project A and B.

\begin{tabular}{|c|c|c|c|}
\hline \multicolumn{2}{|c|}{ Category } & Project A & Project B \\
\hline \multirow{3}{*}{$\begin{array}{c}\text { Project } \\
\text { duration }\end{array}$} & Design & 3 & 3.5 \\
\cline { 2 - 4 } & Construction & 6 & 4.5 \\
\cline { 2 - 4 } & Total & 9 & 8 \\
\hline \multicolumn{2}{|c|}{ Duration to complete } & 8 & 6.5 \\
\hline \multicolumn{2}{|c|}{ Duration saving } & 1 & 1.5 \\
\hline
\end{tabular}

As shown in Table 6 , the cost of each project was also reduced. The final construction cost of project A was $858,640,000$ won, saving $81,360,000$ won. The final construction fee includes the fee for construction project management, which is $5.2 \%$. In other words, the construction manager saved $8.7 \%$ of the cost to the owner, and at the same time he could get the commission for the work. The cost saved by project B is $9.0 \%$ of the total construction cost $(22,500,000$ won), excluding the construction project management fee $(6.0 \%)$.

In both projects, construction period was shortened and construction cost was reduced. The reduction in construction period can lead to an increase in lease income due to premature leasing, which means that the cost savings of more than $10 \%$ have been achieved.

However, in order to maximize the CM effect, the construction project manager needs to participate in the planning/design stage. 
Table 6. Costs of Project A and B.

\begin{tabular}{|c|c|c|}
\hline \multicolumn{2}{|c}{} & (unit: thousand won) \\
\hline Category & Project A & Project B \\
\hline Budget & 940,000 & 250,000 \\
\hline $\begin{array}{c}\text { Cost to complete } \\
\text { (Including CM fee) }\end{array}$ & 858,640 & 227,500 \\
\hline Cost saving & $\begin{array}{c}81,360 \\
(8.7 \%)\end{array}$ & $\begin{array}{l}22,500 \\
(9.0 \%)\end{array}$ \\
\hline CM fee & $5.2 \%$ & $6.0 \%$ \\
\hline
\end{tabular}

\section{Conclusions}

Construction management is also being applied to small-scale construction projects. In addition, the role of local construction management companies should be expanded. This study examines the case of small scale construction management in Jeju and presents the business strategy of a local construction management company. The results of the study are as follows:

(1) According to the cases of a multi-family house and a private house, CM can shorten construction period and reduce construction cost. The CM fee was 5.2\% and $6.0 \%$ of total construction cost, respectively, but the construction cost was reduced by $8.7 \%$ and $9.0 \%$, respectively. Considering the shortened construction period, substantial cost savings are more likely.

(2) A small-scale CM companies needs customized construction management strategies. It is necessary to establish a space to communicate with architects, designers and builders through on-line and off-line, and to use market entry, publicity, and localized business strategies.

This research was supported by Basic Science Research Program through the National Research Foundation of Korea (NRF) funded by the Ministry of Education (No. 2017R1D1A3B03031230).

\section{References}

1. Appraisal and Public Announcement of Construction Management Capacity in 2016, KISCON (Knowledge Information System of Construction Industry), www.kiscon.net/pcm/pcm_info.asp, Aug. 18 (2016)

2. C. S. Oh, G. S. Lee, S. H, Jung, and Y. G. Choi, Research on application of CM at risk for small-medium construction project, Annual Conference of Architectural Institute of Korea, 33, pp.761-762 (2013)

3. S. H. Kim, K. J. Mun, Y. M. Woo, K. J. Koo, and C. T. Hyun, Application of Selective Construction Management Services to Private Small-Medium Construction Projects, Annual Conference of Korea Institute of Construction Engineering and Management, pp.305-309 (2006)

4. Jeju Shin-Bo, Construction Business Recession in Jeju Area, http://www.jejunews.com/news/articleView.html?idxno=2017878, available on July 27 (2017)

5. I. H. You, Construction Specialty and CM at Risk, Construction Management Magazine of Korea Institute of Construction Engineering and Management, 18, pp.15-19 (2017) 
6. Framework Act on Construction Industry, Article 2 (Definitions), Act No.14015, 03 Feb (2016) 